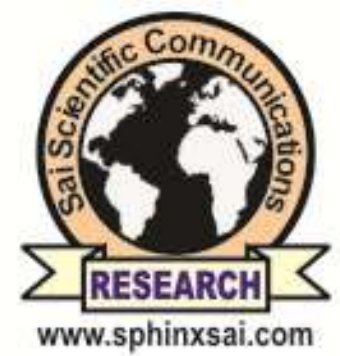

International Journal of PharmTech Research
CODEN (USA): IJPRIF, ISSN: 0974-4304, ISSN(Online): $2455-9563$

Vol.12, No.01, pp 16-23,

2019

\title{
A simple,sensitive and rapid determination of moexipril in human plasma by a novel LC-MS/MS method using solid phase extraction technique
}

\author{
VinayenderAdireddy ${ }^{1,2}$, Vinutha kommineni $^{3}{ }^{3}$ Venkateswarlu Ponneri $^{4}$ \\ ${ }^{1}$ Research Studies, Rayalaseema University, Kurnool-518 002, India \\ ${ }^{2}$ PCR Laboratories, Ramanthapur, Hyderabad-500 013, India \\ ${ }^{3}$ Sri Venkateswara college of pharmacy, Madhapur,Hyderabad-500083 \\ ${ }^{4}$ Analytical and Environmental Chemistry Division, Department of Chemistry, Sri \\ Venkateswara University, Tirupati-517502, India
}

\begin{abstract}
The aim of this work was to develop a simple,sensitive and selective liquid chromatography tandem mass spectrometry assay for quantification ofmoexipril in human plasma. Analytes and the internal standard(stable labelled isotopes) from human plasma by using solid- phase extraction technique with the help of Waters Oasis ${ }^{\circledR}$ HLB 1 cc (30 mg) extraction cartridge. The reconstituted samples were chromatographed on Zorbax XDB C18,4.6*50mm column by using a mixture of acetonitrile $-5 \mathrm{mM}$ ammonium acetate buffer $(80: 20, \mathrm{v} / \mathrm{v})$ as the mobile phase at a flow rate of $0.6 \mathrm{~mL} / \mathrm{min}$. The calibration curve obtained was linear $(r \geq 0.99)$ over the concentration range of $0.102-101.389 \mathrm{ng} / \mathrm{mL}$ for moexipril. Method validation was performed as per FDA guidelines and the results met the acceptance criteria. A run time of $2.2 \mathrm{~min}$ for each sample made it possible to analyze more than 350 human plasma samples per day.
\end{abstract}

Key words : Moexipril; Human plasma; Solid- phase extraction;LC-MS/MS.

\section{Introduction}

Moexipril (Fig. 1) is a potent non-sulfhydryl angiotensin-converting enzyme (ACE) inhibitor used to treat hypertension ${ }^{1}$. It works by relaxing blood vessels, causing them to widen. Lowering high blood pressure helps prevent strokes, heart attacks and kidney problems. Moexipril is a prodrug for moexiprilat, which inhibits ACE in humans and animals. ACE is a peptidyldipeptidase that catalyzes the conversion of the inactive decapeptide angiotensin I to the vasoconstrictor substance angiotensin $\mathrm{II}^{2}$. Angiotensin II is a potent peripheral vasoconstrictor that also stimulates aldosterone secretion by the adrenal cortex and provides negative feedback on renin secretion. ACE is identical to kininase II, an enzyme that degrades bradykinin, an endotheliumdependent vasodilator. Moexiprilat is about 1000 times as potent as Moexipril in inhibiting ACE and kininase II. Inhibition of ACE results in decreased angiotensin II formation, leading to decreased vasoconstriction, increased plasma renin activity, and decreased aldosterone secretion ${ }^{3,4}$.

Vinayender Adireddy et al /International Journal of PharmTech Research, 2019,12(1): 16-23.

DOI: http://dx.doi.org/10.20902//JPTR.2019.120103 
Several analytical methods have been reported for the determination of Moexipril in pure drug, pharmaceutical dosage forms and in biological samples using spectrophotometry ${ }^{5,6}$, HPLC $^{7-10}$, LC-MS $^{11-13}$, GC-MS $^{14}$ [14], spectrofluorimetric ${ }^{15}$ and electro chemical method ${ }^{16}$. The author Karra et al.,2012 published a promising method for determination of moexipril in human plasma using liquid-liquid extraction to extract analytes from plasma. The LLOQ of the method is $0.2 \mathrm{ng} / \mathrm{mL}$.Kotiet al., reported a method for the quantification of moexipril along with its metabolite moexiprilat in rat and human liver microsomal preparation, but this method fails to include complete validation details. Another author, Challaet al., published an LC-MSMS method for the structural identification of degradants of moexipril.

In the present work, we have developed and validated a high throughput LC-MS/MS method for the quantification of moexipril in human plasma with LLOQ of $0.1 \mathrm{ng} / \mathrm{mL}$, which is more sensitive than the reported. The present method employs deuteriated compound as internal standard which is more reliable than the other published methods. In the present method the analyte and internal standard was extracted from plasma using simple one step solid phase extraction.

\section{Material and Methods}

\subsection{LC-MS/MS instrument and conditions}

An HPLC system (Shimadzu, Kyoto, Japan) consisting of a ZorbaxXDB $\mathrm{C}_{18}$ column (50 mm x4.6 mm, $5 \mu \mathrm{m}$; Agilent Technologies, Santa Clara, CA, USA), a binary LC-20AD prominence pump, an auto sampler (SIL-HTc) and a solvent degasser (DGU-20A $\mathrm{A}_{3}$ ) was used for the study. Aliquot of $10 \mu \mathrm{L}$ of the processed samples were injected into the column, which was kept at $40{ }^{\circ} \mathrm{C}$. An isocratic mobile phase consisting of a mixture of acetonitrile $-5 \mathrm{mM}$ ammonium acetate buffer $(80: 20, \mathrm{v} / \mathrm{v})$ was used to separate the analyte from the endogenous components and delivered at a flow rate of $0.6 \mathrm{~mL} / \mathrm{min}$ into the electrospray ionization chamber of the mass spectrometer. Quantification was achieved with MS-MS detection in positive ion mode for the analyte and the IS using an MDS Sciex API-4000 mass spectrometer (Foster City, CA, USA) equipped with a

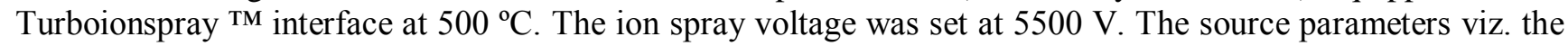
nebulizer gas (GS1), auxiliary gas (GS2), curtain gas and collision gas were set at 40,42, 20, and 6 psi, respectively. The compound parameters viz. the declustering potential (DP), collision energy (CE), entrance potential (EP) and collision cell exit potential (CXP) were 18, 10, 10, $10 \mathrm{~V}$ for moexipril and 18, 9, 10, $9 \mathrm{~V}$ for the IS. Detection of the ions was carried out in the multiple-reaction monitoring mode (MRM), by monitoring the transition pairs of $\mathrm{m} / z 499.4$ precursor ion to the $\mathrm{m} / \mathrm{z} 234.2$ for moexipril and $\mathrm{m} / \mathrm{z} 504.4$ precursor ion to the $\mathrm{m} / \mathrm{z} 239.1$ product ion for the IS. Quadrupoles Q1 and Q3 were set on unit resolution. The analysis data obtained were processed by Analyst Software ${ }^{\mathrm{TM}}$ (version 1.4.2).

\subsection{Preparation of plasma standards and quality controls}

Standard stock solutions of moexipril and IS $(1 \mathrm{mg} / \mathrm{mL})$ were prepared in methanol. Working solutions for calibration and controls were prepared by appropriate dilution in water-methanol (60:40, v/v; diluent). The IS working solution $(200 \mathrm{ng} / \mathrm{mL})$ was prepared by diluting its stock solution with diluent.

Calibration samples were prepared by spiking $950 \mu \mathrm{L}$ of control human plasma with the $50 \mu \mathrm{L}$ working standard solution of the analyte as a bulk, to obtain moexipril concentration levels of $0.102,0.204,0.508,2.536$, 10.140, 20.279,40.556, 60.834, 81.111, $101.389 \mathrm{ng} / \mathrm{mL}$ as a single batch at each concentration. Similarly, quality control (QC) samples were also prepared as a bulk based on an independent weighing of standard drug, at concentrations of 0.104(LLOQ), 0.307 (low), 11.182 (middle 1), 50.826 (middle 2) and $71.155 \mathrm{ng} / \mathrm{mL}$ (high) as a single batch at each concentration. The calibration and control bulk samples were divided into aliquots in micro centrifuge tubes (Tarson, $2 \mathrm{~mL}$ ) and stored in the freezer at $-70 \pm 10^{\circ} \mathrm{C}$ until analyses.

\subsection{Sample processing}

A $100 \mu \mathrm{L}$ aliquot of human plasma sample was mixed with $10 \mu \mathrm{L}$ of the internal standard working solution $\left(200 \mathrm{ng} / \mathrm{mL}\right.$ of moexipril $\mathrm{d}_{5}$ ). To this, $25 \mu \mathrm{L}$ of $0.1 \%$ formic acid solution was added after vortex mixing for $10 \mathrm{~s}$. The sample mixture was loaded onto an Oasis HLB cartridge $(30 \mathrm{mg} / 1 \mathrm{~mL})$ that was preconditioned with $1.0 \mathrm{~mL}$ of methanol followed by $1.0 \mathrm{~mL}$ of water. The extraction cartridge was washed with 
$1.0 \mathrm{~mL}$ of $0.1 \%$ formic acid solution followed by $1.0 \mathrm{~mL}$ of $5 \%$ methanol. Analyte and IS were eluted with 0.5 $\mathrm{mL}$ of mobile phase. Aliquot of $10 \mu \mathrm{L}$ of the extract was injected into the chromatographic system.

\subsection{Bioanalytical method validation}

The validation of the above method was carried out as per US FDA guidelines ${ }^{18}$. The parameters determined were selectivity, specificity, sensitivity, matrix effect, linearity, precision, accuracy, recovery, dilution integrity and stability.

\section{Results and discussion}

\subsection{Method development}

To develop a rapid, sensitive and simple assay method for the extraction and quantification of moexipril during method development different options were evaluated to optimize detection and chromatography parameters. The inherent selectivity of MS/MS detection was also expected to be beneficial in developing a selective and sensitive method. Protonated form of analyte and IS, $[\mathrm{M}+\mathrm{H}]^{+}$ion was the parent ion in the $\mathrm{Q}_{1}$ spectrum and was used as the precursor ion to obtain $\mathrm{Q}_{3}$ product ion spectra. The most sensitive mass transition was observed from m/z 234.2 to 154.1 for moexipril (Fig 1A) and from m/z 239.1 to 159.1 for the IS (Fig 1B).

Chromatographic conditions, especially the composition of the mobile phase, column type, flow rate and column oven temperature were optimized through several trials to achieve good resolution and increased intensity of the signals of the analyte and IS, as well as for the short run time. Separation was attempted using various combinations of methanol, acetonitrile and buffer with varying contents of each component on different columns like $\mathrm{C}_{8}$ and $\mathrm{C}_{18}$ of different makes like Grace, Chromolith, BDS Hypersil, Hypurity advance, Zorbax, Kromasil, Ace and Intertsil etc. It was found that a mixture of acetonitrile and 5mM ammonium acetate (80:20, $\mathrm{v} / \mathrm{v}$ ) could achieve this purpose and was finally adopted as the mobile phase.ZorbaxXDB $\mathrm{C}_{18}$ column (50 mm $\mathrm{x} 4.6 \mathrm{~mm}, 5 \mu \mathrm{m}$ ) gave good peak shape and response even at lowest concentration level for the analyteand IS. The mobile phase was operated at a flow rate of $0.6 \mathrm{~mL} / \mathrm{min}$. The retention time of analyte and the IS were low enough (1.0min) allowing a small run time of $2.2 \mathrm{~min}$.

Due to high drug protein binding, protein precipitation (PP) was tried initially using acetonitrile and methanol as precipitating agents but the response was inconsistent especially at the LLOQ level. Thus, the simple SPE technique was employed for the sample preparation in this work and provided high recoveries of the drugs. The use of stable labeled isotopes of the analyte as an ISis recommended for bio analytical assays to increase assay precision and limit variable recovery between analyte and the IS For an LC-MS/MS analysis, utilization of stable isotope-labeled drugs as IS proves to be helpful when a significant matrix effect is possible. At the initial stages of this work, several compounds were investigated to find a suitable IS and finally moexipril stable labeled isotope moexipril $\mathrm{d}_{5}$ was found to be best for the present purpose.

\subsection{Selectivity and chromatography}

The selectivity of the method was examined by analyzing blank human plasma extract (Fig. 1A) and an extract spiked only with the IS As shown in Fig. 1A, no significant direct interference in the blank plasma traces was observed from endogenous substances in drug-free human plasma at the retention time of the analyte and IS Moexipril-d5. Also, no interference was observed from the IS at retention time of analyte (Fig 1B). 

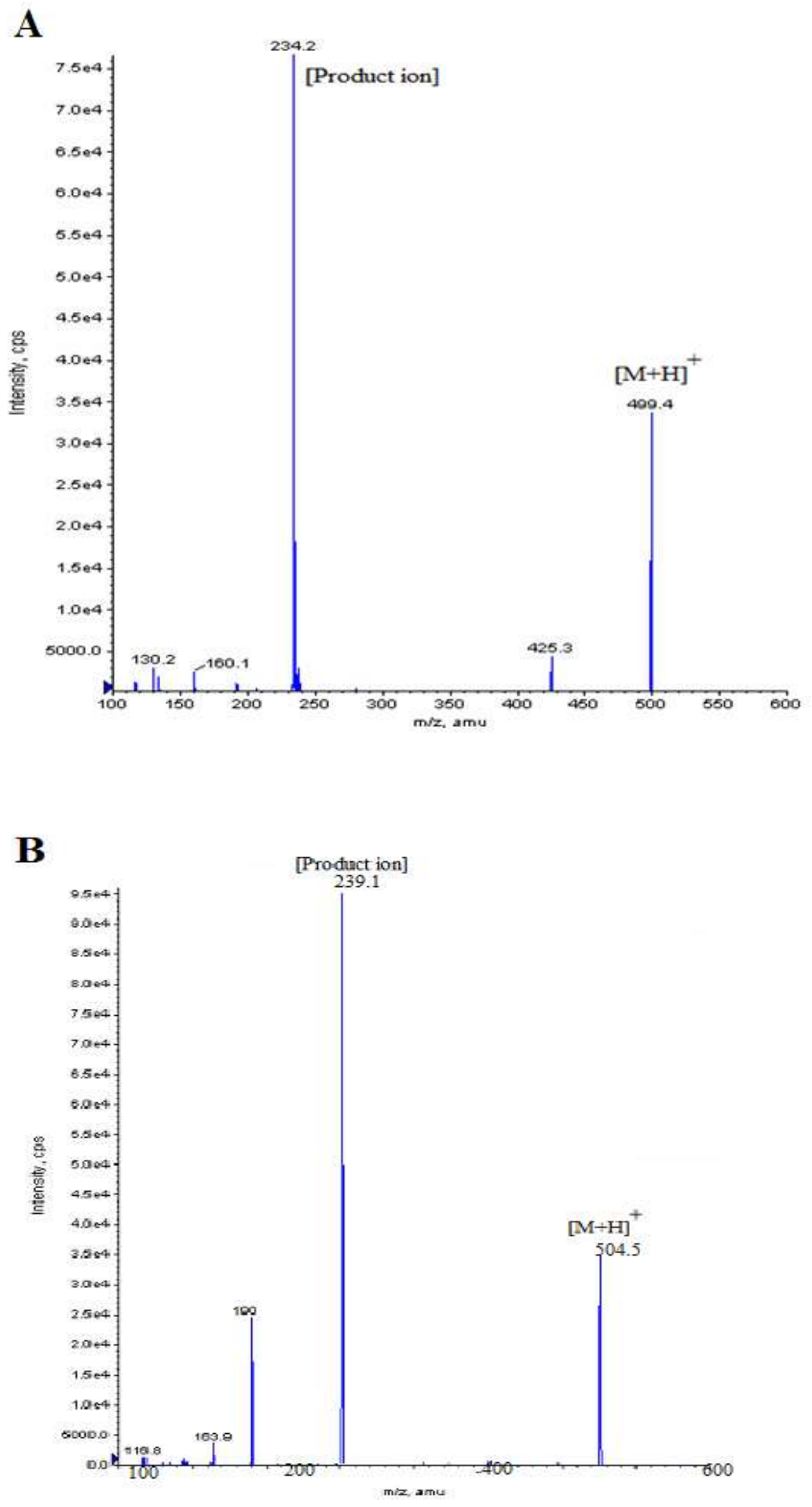

Figure 1: Product ion mass spectra of $[\mathrm{M}+\mathrm{H}]^{+}$of (A) moexipril and (B) and IS.

\subsection{Sensitivity}

The lowest limit of reliable quantification (Fig 1C) for the analyte was set at the concentration of the LLOQ. The precision and accuracy of analyte at LLOQ concentration was found to be 1.91 and $95.42 \%$, respectively. 
A

m/z: 499.4/234.2

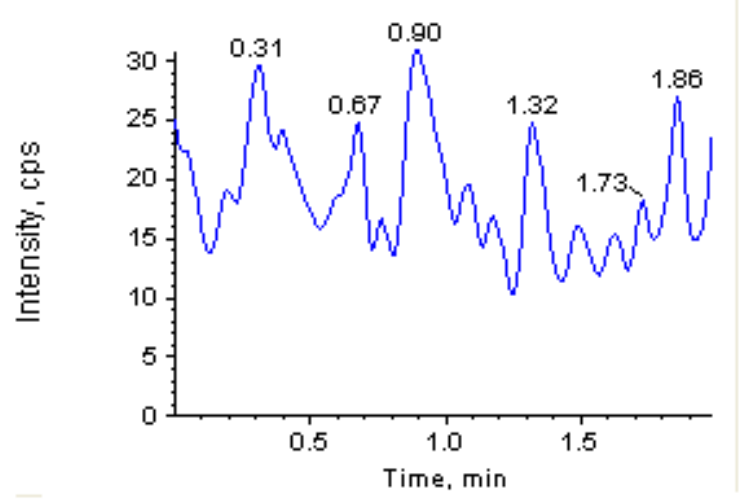

B

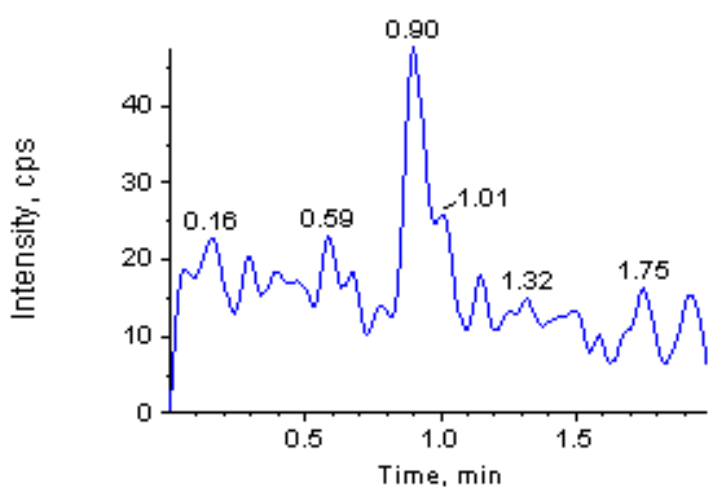

C

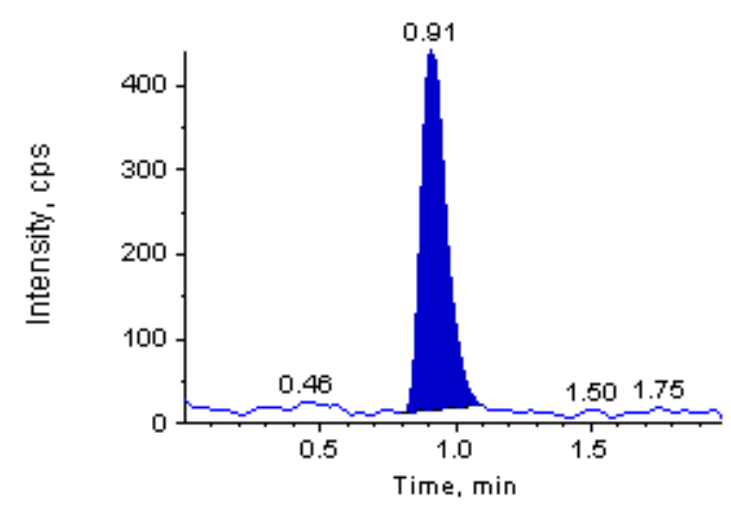

$\mathrm{m} / \mathrm{z}: 504.5 / 239.0$

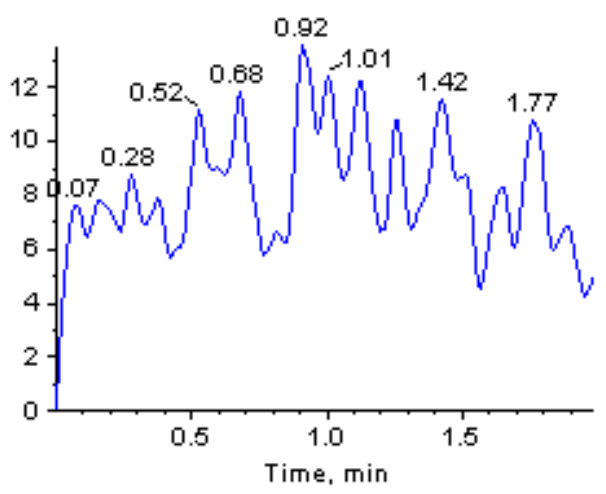

$\mathrm{m} / \mathrm{z}: \mathbf{5 0 4 . 5 / 2 3 9 . 0}$

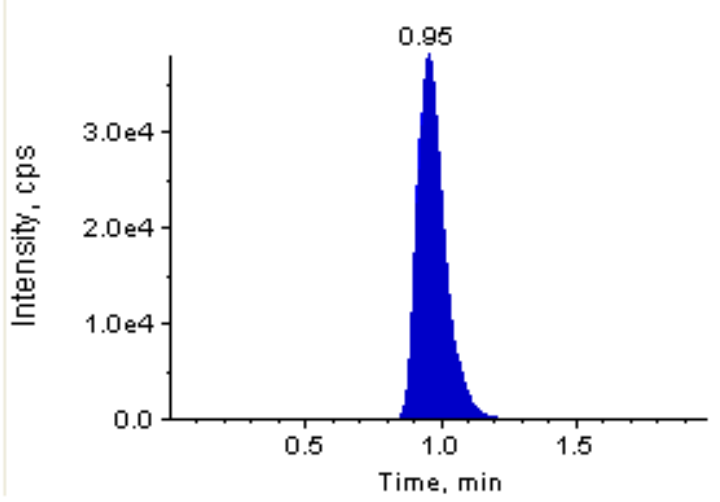

$\mathrm{m} / \mathrm{z}: \mathbf{5 0 4 . 5 / 2 3 9 . 0}$

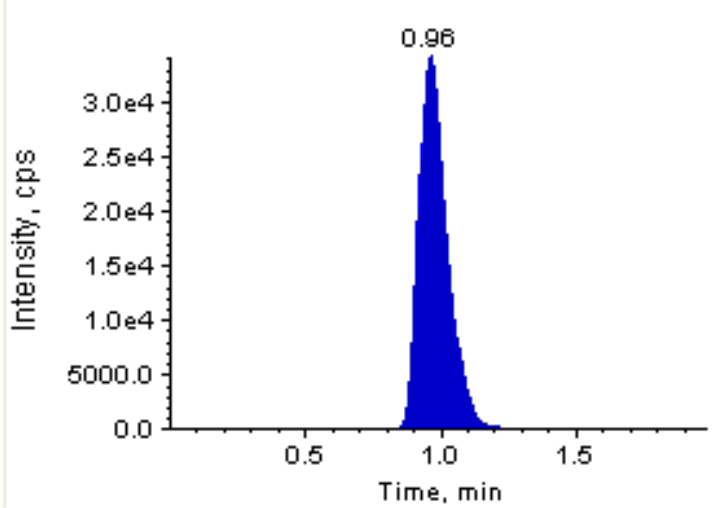

Figure 2: Typical MRM chromatograms of moexipril (left panel) and IS (right panel) in human blank plasma (A), and human plasma spiked with IS (B), a LLOQ sample along with IS (C).

\subsection{Matrix effect}

Matrix effect assessment was done with the aim to check the effect of different lots of plasma on the back calculated value of QC's nominal concentration. The results found were well within the acceptable limits. No significant matrix effect was observed in all the six batches of human plasma for the analyte at low and high quality control concentrations. Also, the extraction method was rugged enough and gave accurate and consistent results when applied to real subject samples. 


\subsection{Linearity, precision and accuracy}

The analyte showed good linearity in the concentration rage of $1.02-101.389 \mathrm{ng} / \mathrm{mL}$. Both the regression models $\left(1 / \mathrm{x}\right.$ and $\left.1 / \mathrm{x}^{2}\right)$ were compared and best fit for the concentration-detector response relationship was obtained with a weighting factor of $1 / \mathrm{x}^{2}$. The mean correlation coefficient was $\geq 0.99$ for all the analytical runs generated during entire course of validation.

The intra-day and inter-day precision and accuracy results in plasma QC samples are summarized in Table 1. The precision (\% CV) and accuracy values of Moexiprilfor intra- and inter-day ranged from 0.16$10.13 \%$ and $96.25-108.77 \%$, and $4.28-6.15 \%$ and $97.10-104.97 \%$, respectively. The results revealed good precision and accuracy.

Table 1: Precision and accuracy data for moexipril

\begin{tabular}{|c|c|c|c|c|}
\hline $\begin{array}{l}\text { Quality } \\
\text { control }\end{array}$ & Run & $\begin{array}{l}\text { Concentration found (mean } \\
\pm \mathrm{SD} ; \mathrm{ng} / \mathrm{mL} \text { ) }\end{array}$ & \begin{tabular}{|l} 
Precision \\
$(\%)$
\end{tabular} & \begin{tabular}{|l} 
Accuracy \\
$(\%)$
\end{tabular} \\
\hline \multicolumn{5}{|c|}{ Intra-day variations ( $n=6$ at each concentration) } \\
\hline \multirow{3}{*}{ LLOQ } & 1 & $0.109 \pm 0.011$ & 10.13 & 108.49 \\
\hline & 2 & $0.107 \pm 0.004$ & 4.43 & 103.37 \\
\hline & 3 & $0.106 \pm 0.003$ & 3.67 & 102.72 \\
\hline \multirow{3}{*}{ LQC } & 1 & $0.305 \pm 0.026$ & 8.68 & 99.62 \\
\hline & 2 & $0.301 \pm 0.009$ & 3.05 & 98.21 \\
\hline & 3 & $0.295 \pm 0.004$ & 1.46 & 96.25 \\
\hline \multirow{3}{*}{ MQC1 } & 1 & $11.312 \pm 1.025$ & 9.07 & 101.16 \\
\hline & 2 & $10.947 \pm 0.228$ & 2.08 & 97.90 \\
\hline & 3 & $10.808 \pm 0.050$ & 0.46 & 96.66 \\
\hline \multirow{3}{*}{ MQC2 } & 1 & $55.282 \pm 5.600$ & 10.13 & 108.77 \\
\hline & 2 & $53.313 \pm 0.813$ & 1.52 & 104.89 \\
\hline & 3 & $52.606 \pm 0.086$ & 0.16 & 103.50 \\
\hline \multirow{3}{*}{ HQC } & 1 & $73.447 \pm 6.534$ & 8.90 & 103.22 \\
\hline & 2 & $71.856 \pm 0.515$ & 0.72 & 100.99 \\
\hline & 3 & $71.741 \pm 0.398$ & 0.55 & 100.82 \\
\hline \multicolumn{5}{|c|}{ Inter-day variations ( $n=18$ at each concentration) } \\
\hline \multicolumn{2}{|c|}{ LLOQ } & $0.109 \pm 0.006$ & 6.15 & 104.97 \\
\hline \multicolumn{2}{|l|}{ LQC } & $0.298 \pm 0.013$ & 4.53 & 97.10 \\
\hline \multicolumn{2}{|l|}{ MQC1 } & $10.956 \pm 0.500$ & 4.57 & 97.98 \\
\hline \multicolumn{2}{|l|}{ MQC2 } & $53.262 \pm 2.705$ & 5.08 & 104.79 \\
\hline \multicolumn{2}{|l|}{$\mathrm{HQC}$} & $72.023 \pm 3.079$ & 4.28 & 101.22 \\
\hline
\end{tabular}

\subsection{Recovery and dilution integrity}

The mean overall recovery of moexipril was $72.55 \pm 7.82 \%$ with the precision range of $1.47-9.27 \%$ and the recovery of IS was $78.95 \%$ with the precision range of 3.56-4.05\%. Good and reproducible recoveries were obtained for the analyte and the IS. Thus, the assay has been proved to be robust in high throughput bioanalysis.

The upper concentration limit of moexipril can be extended to $86.402 \mathrm{ng} / \mathrm{mL}$ for by $1 / 2$ and $1 / 4$ dilutions with screened human blank plasma. The precision $(\% \mathrm{CV})$ for dilution integrity of $1 / 2$ and $1 / 4$ dilution was found to be $0.59 \%$ and $0.69 \%$, while the accuracy results were found to be $107.66 \%$ and $108.23 \%$, respectively. 
All the stability results were presented in Table 2 .

Table 2: Stability data for moexipril in plasma $(n=6)$

\begin{tabular}{|c|c|c|c|c|}
\hline Stability test & $\begin{array}{l}\text { QC spiked concentration } \\
(\mathrm{ng} / \mathrm{mL})\end{array}$ & $\underset{(\mathrm{ng} / \mathrm{mL})}{\operatorname{Mean}} \pm$ SD & $\begin{array}{l}\text { Precision } \\
(\%)\end{array}$ & $\begin{array}{l}\text { Accuracy/ } \\
\text { Stability }(\%)\end{array}$ \\
\hline \multirow[t]{2}{*}{ Process $^{\mathrm{a}}$} & 0.307 & $0.279 \pm 0.003$ & 1.09 & 90.88 \\
\hline & 71.155 & $67.286 \pm 0.607$ & 0.90 & 94.56 \\
\hline \multirow[t]{2}{*}{ Process $^{\mathrm{b}}$} & 0.307 & $0.285 \pm 0.004$ & 1.45 & 93.05 \\
\hline & 71.155 & $66.709 \pm 0.686$ & 1.03 & 93.75 \\
\hline \multirow[t]{2}{*}{ Bench top $^{c}$} & 0.307 & $0.268 \pm 0.005$ & 1.95 & 87.51 \\
\hline & 71.155 & $66.653 \pm 0.600$ & 0.90 & 950.67 \\
\hline \multirow[t]{2}{*}{$\mathrm{FT}^{\mathrm{d}}$} & 0.307 & $0.282 \pm 0.004$ & 1.46 & 92.07 \\
\hline & 71.155 & $66.674 \pm 0.433$ & 0.65 & 93.70 \\
\hline \multirow[t]{2}{*}{ Reinjection $^{\mathrm{e}}$} & 0.307 & $0.283 \pm 0.005$ & 1.88 & 92.18 \\
\hline & 71.155 & $67.092 \pm 0.596$ & 0.89 & 94.29 \\
\hline \multirow[t]{2}{*}{ Long-term ${ }^{\mathrm{f}}$} & 0.307 & $0.275 \pm 0.007$ & 2.78 & 89.38 \\
\hline & 71.155 & $67.209 \pm 0.430$ & 0.64 & 94.59 \\
\hline \multicolumn{5}{|c|}{$\begin{array}{l}{ }^{\mathrm{a}} \text { after } 75 \mathrm{~h} \text { in autosampler at } 10^{\circ} \mathrm{C} ;{ }^{\mathrm{b}} \text { after } 72 \mathrm{~h} \text { at } 2-8^{\circ} \mathrm{C} ;{ }^{\mathrm{c}} \text { after } 12 \mathrm{~h} \text { at room temperature; }{ }^{\mathrm{d}} \text { after } 4 \text { freeze } \\
\text { and thaw cycles; }{ }^{\mathrm{e}} \text { after } 29 \mathrm{~h} \text { of Reinjection; } \\
{ }_{\mathrm{f}} \text { at }-70^{\circ} \mathrm{C} \text { for } 58 \text { days }\end{array}$} \\
\hline
\end{tabular}

\subsection{Conclusion.}

The LC-MS/MS assay presented in this paper is rapid, simple, specific and sensitive for quantification of moexipril in human plasma and is fully validated according to commonly acceptable FDA guidelines. To the best of knowledge, this is the first LC-MS/MS report for the determination of moexipril in human plasma with isotopic labelled IS. The method showed suitability for pharmacokinetic studies in humans. The extraction method gave high, consistent and reproducible recoveries for the analyte and IS from plasma. The costeffectiveness, simplicity of the assay and usage of Solid phase extraction which has very minimal matrix effect and sample turnover rate of less than 2.2 min per sample, make it an attractive procedure in high-throughput bioanalysis of moexipril.

\section{References}

1. Martindale, The Complete Drug Reference, 34th Edn, pharmaceutical press, (2005), p. 961,

2. The Merck Index, 13th Edn., Merck Research Laboratories, Merck \& Co., White House Station, NJ, USA,(2001), p. 1112.

3. H.L.Sharma\&K.K.Sharma, Principles of pharmacology, 2nd Edn, Paras's medical publishers, Delhi,, (2012), p. 254.

4. www.drugbank.ca/drugs/DB00691.

5. Abd El Kawy. M, El Gindy. A.E, Hegazy. M and Shokry. E.S. Novel spectrophotometric method for simultaneous determination of two binary mixtures containing Hydrochlorothiazide by ratio subtraction. Journal of Applied Sciences Research, (2010),6(8), 918-926.

6. Stanisz. B, Regulska. K and Ratajczak. T. First order derivative spectrophotometric and HPLC methods for determination of Moexipril hydrochloride in the pure form, 282pharmeceutical formulations and evaluation of its stability. ActaPoloniac Pharmaceutical Drug Research, (2012),69(3), 389-395.

7. Erturk. S, Cetin. S.M and Atmaca. S. Simultaneous determination of Moexipril hydrochloride and Hydrochlorothiazide in tablets by derivative spectrophotometric and high-performance liquid chromatographic methods. Journal of Pharmaceutical and Biomedical Analysis, (2003);33(3), 505-511. doi:10.1016/S0731-7085(03)00252-8

8. Manjulatha. Y.B and Gowrisankar. D. Development and validation of a stability indicating RP-HPLC method for the quantitative analysis of Moexipril. International Journal of Universal Pharmacy and Life Sciences, (2011),1(3), 156-165. 
9. Elshanawane. A.A, Mostafa. S.M and Elgawish M.S. Application of a validated stability-indicating LC method to stress degradation studies of Ramipril and MoexiprilHCl. Chromatographia, (2008),67, 567573. doi:10.1365/s10337-008-0544-3

10. Wyszomirska. E, Czerwiska. K and Mazurek. P.A. Identification and determination of antihypertonics from the group of angiotensin convertase inhibitors by densitometric method in comparition with HPLC method. ActaPoloniaePharmaceutica Drug Research,(2010), 67(2 ), 137-143.

11. Koti. J, Hada. V, Petroianu. G, Hasan. M.Y, Tekes. K, Szuca. Z. and Kalasz. H. Monitoring the metabolism of Moexipril to Moexiprilat using high-performance liquid chromatography-electrospray ionization mass spectrometry. Journal of Chromatographic Science,(2006), 44(4), 214-218. doi:10.1093/chromsci/44.4.214.

12. Biomed Chromatogr. 2017 Nov;31(11). doi: 10.1002/bmc.4004. Epub 2017 Jun 7. doi:10.1002/bmc.4004.

13. Karra. V.K, Mullangi. R, Pilli. N.R, Inamadugu. J.K, Ravi. V.B and SeshagiriRao. J.V.L.N. A rapid and sensitive liquid chromatography-tandem mass spectrometric assay for Moexipril, an angiotensinconverting enzyme inhibitor in human plasma. Biomedical Chromatography, (2012),26(12), 1552-8. doi:10.1002/bmc.2731.

14. Hammes. W, Hammes. B, Buechsler. U, Paar. F and Boekens. H. Simultaneous determination of Moexipril and Moexiprilat, its active metabolite, in human plasma by gas chromatography-negative-ion chemical ionization mass spectrometry. Journal of Chromatography and Biomedical Applications,(1995), 670, 81-89. doi:10.1016/0378-4347(95)00135-6.

15. El-Hay. S.S, Colyer. C.L, Hassan. W.S and Shalaby. A. Spectrofluorimetric determination of Etodolac, MoxeprilHCl and Fexofenadine $\mathrm{HCl}$ using europium sensitized fluorescence in bulk and pharmaceutical preparations. Journal of Fluorescence,(2012), 22(1), 247-52. doi:10.1007/s10895-0110954-8.

16. Csermely. T, Kalasz. H, Deak. K, Hasan.,Darvas. F and Petroianu. G. Lipophilicity determination of some ACE inhibitors by TLC. Journal of Liquid Chromatography and Related Technologies, (2008),31, 2019-2034. doi:10.1080/10826070802198410.

17. Attia. A.K. Determination of antihypertensive drug Moexipril hydrochloride based on the enhancement effect of sodium dodecyl sulfate at carbon paste electrode. Talanta, (2010), 81, 25-29. doi:10.1016/j.talanta.2009.11.031.

18. US DHHS, FDA and CDER. Guidance for Industry: Bioanalytical Method Validation. US Department of Health and Human Services, Food and Drug Administration, Center for Drug Evaluation and Research and Center for Veterinary Medicine, 2001. Available at: http://www/ fda.gov/cder/guidance/index.htm.

19. Matta MK, Narayanasamy S, Thomas CD, Lin X, Stewart S, Chockalingam A, Patel V, Rouse R. A sensitive UPLC-APCI-MS/MS method for the determination of dexamethasone and its application in an ocular tissue distribution study in rabbits following topical administration. Analytical Methods, 2018,10, 2307-2316. doi:10.1039/C8AY00283E. 